\title{
Gambaran Klinis Asidosis Tubulus Renalis pada Anak
}

\author{
Sudung O. Pardede, Partini P. Trihono, Taralan Tambunan
}

\begin{abstract}
Asidosis tubulus renalis merupakan penyakit yang jarang dijumpai, mempunyai manifestasi klinis yang tidak spesifik; ditandai dengan asidosis metabolik hiperkloremik, senjang anion plasma dan laju filtrasi glomerulus normal. Gambaran klinis dapat berupa gangguan pertumbuhan, anoreksia, muntah, konstipasi, diare, dehidrasi, dan poliuria. Penelitian ini merupakan penelitian retrospektif deskriptif terhadap pasien asidosis tubulus renalis primer maupun sekunder di Bagian Ilmu Kesehatan Anak FKUI-RSCM Jakarta antara tahun 1975-1995. Selama 20 tahun didapatkan 12 kasus asidosis tubulus renalis yang terdiri dari 6 anak laki-laki dan 6 perempuan. Usia saat diagnosis ditegakkan antara 4 bulan sampai 11 tahun, rerata 5 tahun 2 bulan. Asidosis tubulus renalis distal merupakan jenis yang paling sering ditemukan yaitu 8 pasien, sedangkan asidosis tubulus renalis proksimal 4 pasien. Gangguan motorik tungkai bawah merupakan keluhan utama yang paling sering ditemukan yaitu pada $9 / 12$ pasien ( 7 pasien tidak dapat berjalan atau lumpuh dan 2 pasien dengan tulang bengkok dan fraktur). Muntah-muntah disertai dehidrasi merupakan keluhan utama pada 2 pasien sedangkan gagal tumbuh pada 1 pasien. Malnutrisi dengan berat badan < P3 NCHS didapatkan pada 10 pasien sedangkan gangguan pertumbuhan dengan tinggi badan < P3 NCHS didapatkan pada 11 pasien. Sebagai kesimpulan, asidosis tubulus renalis merupakan penyakit yang sangat jarang dengan manifestasi klinis yang tidak spesifik sehingga diagnosis seringkali terlambat. Gangguan motorik tungkai bawah merupakan keluhan utama yang paling sering ditemukan.
\end{abstract}

Kata kunci: asidosis tubulus renalis, asidosis metabolik hiperkloremik, senjang anion.

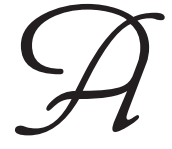

sidosis tubulus renalis (ATR) adalah sindrom klinik yang disebabkan oleh ketidakmampuan ginjal untuk menjaga perbedaan $\mathrm{pH}$ normal antara darah dan lumen tubulus ginjal. Gangguan yang terjadi berupa gangguan reabsorbsi bikarbonat pada tubulus ginjal, gangguan ekskresi $\mathrm{H}^{+}$, atau keduanya sehingga menyebabkan asidosis metabolik yang terus menerus. ${ }^{1,2,3,4}$ Asidosis Tubulus Renalis ditandai adanya asidosis metabolik hiperkloremik dengan senjang anion plasma dan laju filtrasi glomerulus normal. Manifestasi klinis ATR tidak

Alamat Korespondensi:

Dr. Sudung O. Pardede, Sp.A.

Staf Subbagian Nefrologi. Bagian Ilmu Kesehatan Anak FKUI-RSCM. Jl. Salemba no. 6, Jakarta 10430.

Telepon: 021-3915179. Fax.: 021-390 7743. spesifik dapat berupa gangguan pertumbuhan, anoreksia, muntah, konstipasi, diare, dehidrasi dan poliuria. ${ }^{1}{ }^{2}$ Diagnosis dini dan tata laksana yang adekuat sangat penting untuk mencegah komplikasi seperti gagal tumbuh, nefrokalsinosis, nefrolitiasis, dan gagal ginjal. ${ }^{3,5}$ ATR dapat dibedakan menjadi 4 tipe yaitu tipe I atau distal, tipe II atau proksimal, tipe III atau hibrid, dan tipe IV atau ATR hiperkalemik. ${ }^{1,4,6}$

Asidosis tubulus renalis merupakan penyakit yang jarang; pada penelusuran kepustakaan, belum ada penelitian tentang ATR pada anak di Indonesia, selain laporan kasus. Penelitian ini dilakukan untuk memperoleh gambaran klinis asidosis tubulus renalis di Bagian Ilmu Kesehatan Anak FKUI-RSCM. Dengan demikian diharapkan kewaspadaan terhadap ATR akan meningkat sehingga diagnosis dan tata laksana dini yang adekuat dapat dilakukan untuk mencegah timbulnya komplikasi. 


\section{Bahan dan Cara}

Penelitian merupakan penelitian retrospektif deskriptif terhadap pasien ATR primer maupun sekunder di Bagian Ilmu Kesehatan Anak FKUI-RSCM Jakarta antara tahun 1975 sampai dengan tahun 1995. Diagnosis ATR ditegakkan berdasarkan manifestasi klinis berupa asidosis metabolik hiperkloremik, senjang anion plasma yang normal, gagal tumbuh, muntah berulang, poliuria, dehidrasi, kontipasi, dengan urinalisis yang normal kecuali $\mathrm{pH}$ urin yang alkali. Senjang anion urin diperiksa untuk menentukan jenis ATR. Data penelitian diperoleh dari catatan medik yang meliputi identitas, gambaran klinis, pemeriksaan laboratorium, dan keadaan terakhir pasien; disajikan dalam bentuk tekstular dan tabular.

\section{Hasil}

Selama 20 tahun (1975-1995) didapatkan 13 kasus ATR, 1 kasus tidak dimasukkan ke dalam penelitian karena data yang tidak akurat; sehingga yang dilaporkan 12 kasus ATR yang terdiri dari 6 laki-laki dan 6 perempuan. Usia saat diagnosis ditegakkan berkisar antara 4 bulan sampai 11 tahun dengan rerata usia 5 tahun 2 bulan. Pasien termuda didapatkan pada bayi berusia 4 bulan dengan gejala klinis berupa kesulitan makan dan muntah berulang yang terjadi segera setelah lahir; pasien ini datang ke RSCM dalam keadaan dehidrasi.

Pada Tabel 1, antara tahun 1975 sampai dengan 1987, (selama 12 tahun) hanya didapatkan seorang anak laki-laki dengan ATR, dan antara tahun 1988 sampai 1995 (selama 8 tahun) dijumpai 11 kasus ATR. Pada tahun 1988 didapatkan 1 laki-laki dan 2 perempuan, sampai dengan tahun 1994 didapatkan 4 pasien yang semuanya perempuan, dan pada tahun 1995 didapatkan 4 pasien ATR yang semuanya laki-laki.

Asidosis tubulus renalis distal merupakan jenis yang paling sering ditemukan (8 pasien) dan ATR proksimal 4 pasien; Asidosis tubulus renalis distal terdiri dari 5 laki-laki dan 3 perempuan, sedangkan ATR proksimal terdiri dari 1 laki-laki dan 3 perempuan. Lama waktu antara keluhan pertama kali sampai diagnosis ditegakkan bervariasi antara 2 bulan sampai 4 tahun (rerata 1 tahun 3 bulan). Keluhan utama yang paling sering adalah gangguan motorik tungkai bawah, ditemukan pada 9 pasien yaitu 7 pasien tidak dapat berjalan atau lumpuh dan 2 pasien dengan tulang bengkok dan fraktur.
Muntah disertai dehidrasi didapatkan pada 2 pasien, sedangkan gagal tumbuh pada 1 pasien. Pada kedua pasien dengan kelainan tulang, diagnosis ATR ditegakkan setelah terjadi manifestasi klinis berturutturut selama 2 bulan dan 1 tahun 6 bulan. Sepuluh kasus menderita malnutirisi dengan berat badan $<\mathrm{P} 3 \mathrm{NCHS}$ dan 2 kasus dengan berat badan normal. Pada 11 kasus terjadi gangguan pertumbuhan dengan tinggi badan $<$ P3NCHS dan 1 pasien dengan tinggi badan normal. Insufisiensi ginjal hanya didapatkan pada 1 kasus dengan penyebab yang tidak diketahui.

Hasil pemeriksaan laboratorium (Tabel 2) memperlihatkan $\mathrm{pH}$ darah $<7,3$ pada $7 / 12$ pasien, kadar $\mathrm{HCO}_{3}$ rendah pada $12 / 12$ pasien, hipokalemia 9/12, hiperkloremia $11 / 12$, dan peningkatan kadar fosfatase alkali yang meningkat pada 7/12 pasien. Senjang anion plasma normal didapatkan pada 11 kasus, 1 kasus insufisiensi ginjal mempunyai senjang anion plasma tinggi (kasus no. 8). Rentang nilai $\mathrm{pH}$ plasma berkisar antara 7,07 - 7,37; $\mathrm{HCO}_{3}$ antara 6,5 20,4 mEq/l; BE antara (- 22,4) - (- 5,0); kalium 2,0 4,0 mEq/l; natrium 132 - $152 \mathrm{mEq} / \mathrm{l}$; klor 100 -122 $\mathrm{mg} / \mathrm{ml}$; senjang anion plasma 8 - 21,1; ureum 18 - 39 $\mathrm{mg} / \mathrm{dl}$; dan kreatinin 0,4-1,2 mg/dl. Sedangkan $\mathrm{pH}$ urin $>6$ didapatkan pada 9 pasien rentang $(\mathrm{pH}$ urin $5,0-8,0)$; dan senjang anion urin positif didapatkan pada 7 kasus.

Delapan kasus didiagnosis sebagai RTA distal primer berdasarkan manifestasi klinis, asidosis metabolik hiperkloremik, senjang anion darah normal, senjang anon urin positif, adanya kelainan tulang dan nefrokalsinosis. Empat kasus lainnya adalah ATR proksimal. Dua di antara kasus ATR proksimal ini merupakan sindrom Fancony (kasus 5 dan 6), satu pasien (kasus 9) merupakan ATR proksimal dengan penyakit primer yang tidak diketahui. Satu pasien (kasus no. 7) merupakan kasus yang kompleks dengan anomali kongenital, kandung kemih neurogenik, dan meningokel. Dalam pemantauan selanjutnya, pasien ini menderita leukemia limfositik akut dan diberikan terapi sitostatik sesuai protokol, sehingga mengalami remisi. Bersamaan dengan keadaan remisi, manifestasi klinis ATR menghilang sehingga pada kasus ini ATR proksimal diduga disebabkan oleh leukemia. Namun, pasien ini kemudian meninggal setelah menderita hepatitis B dan gagal hati.

Nefrokalsinosis didapatkan pada 2 pasien yang keduanya menderita ATR distal (kasus no. 1 dan 4). Pada kasus 1, nefrokalsinosis timbul setelah pengobatan 
Sari Pediatri, Vol. 4, No. 4, Maret 2003

Tabel 1. Karakteristik pasien Asidosis Tubulus Renalis di Bagian IKA FKUI-RSCM (1975-1995)

\begin{tabular}{|c|c|c|c|c|c|c|c|c|c|}
\hline No. & $\begin{array}{c}\text { Jenis } \\
\text { kelamin }\end{array}$ & $\begin{array}{c}\text { Umur } \\
\text { (thn,bln) }\end{array}$ & $\begin{array}{c}\mathrm{BB} \\
(\mathrm{kg})\end{array}$ & $\begin{array}{l}\text { TB } \\
(\mathrm{cm})\end{array}$ & $\begin{array}{l}\text { Tahun } \\
\text { rawat }\end{array}$ & $\begin{array}{l}\text { Keluhan } \\
\text { utama }\end{array}$ & Diagnosis & $\begin{array}{l}\text { Lama } \\
\text { pengamatan } \\
\text { (thn) }\end{array}$ & Prognosis \\
\hline 1. & $\begin{array}{c}\mathrm{L} \\
(<\mathrm{p} 3)\end{array}$ & $\begin{array}{l}5.0 \\
(<\mathrm{p} 3)\end{array}$ & 11 & 83 & $\begin{array}{c}\text { Novemb } \\
1975\end{array}$ & Lumpuh & $\begin{array}{l}\text { ATR distal } \\
\text { Nefrokalsinosis } \\
\text { ISK }\end{array}$ & 18 & Hidup \\
\hline 2. & $\mathrm{P}$ & 4.3 & $\begin{array}{l}8.7 \\
(<\mathrm{p} 3)\end{array}$ & $\begin{array}{c}79 \\
(<\mathrm{p} 3)\end{array}$ & $\begin{array}{c}\text { Maret } \\
1988\end{array}$ & $\begin{array}{l}\text { Tidak dapat } \\
\text { berjalan }\end{array}$ & ATR distal & 7.9 & Hidup \\
\hline 3. & $\mathrm{~L}$ & 3.4 & $\begin{array}{c}8.9 \\
(<\mathrm{p} 3) \\
\end{array}$ & $\begin{array}{c}77 \\
(<\mathrm{p} 3)\end{array}$ & $\begin{array}{c}\text { Juli } \\
1988 \\
\end{array}$ & $\begin{array}{l}\text { Tidak dapat } \\
\text { berjalan }\end{array}$ & ATR distal & 7.4 & Hidup \\
\hline 4. & $\mathrm{P}$ & 12.0 & $\begin{array}{c}29 \\
(<\mathrm{p} 3)\end{array}$ & $\begin{array}{l}130 \\
(<\mathrm{p} 3)\end{array}$ & $\begin{array}{l}\text { Agustus } \\
1988\end{array}$ & $\begin{array}{l}\text { Fraktur } \\
\text { lengan kiri } \\
\text { Pincang }\end{array}$ & $\begin{array}{l}\text { ATR distal } \\
\text { Nefrokalsinosis }\end{array}$ & 6,0 & Hidup \\
\hline 5. & $\mathrm{P}$ & 5.0 & $\begin{array}{c}7.7 \\
(<\mathrm{p} 3)\end{array}$ & $\begin{array}{c}76 \\
(<\mathrm{p} 3)\end{array}$ & $\begin{array}{l}\text { Juni } \\
1990\end{array}$ & $\begin{array}{l}\text { Tidak dapat } \\
\text { berjalan }\end{array}$ & $\begin{array}{l}\text { Sindr. Fancony } \\
\text { (ATR proksimal) }\end{array}$ & 2.0 & U \\
\hline 6. & $\mathrm{P}$ & 7.0 & $\begin{array}{c}9.3 \\
(<\mathrm{p} 3)\end{array}$ & $\begin{array}{l}83.5 \\
(<\mathrm{p} 3)\end{array}$ & $\begin{array}{c}\text { Juli } \\
1991\end{array}$ & $\begin{array}{l}\text { Tidak dapat } \\
\text { berjalan }\end{array}$ & $\begin{array}{l}\text { Sindr. Fancony } \\
\text { (ATR proksimal) }\end{array}$ & 2.0 & $\mathrm{U}$ \\
\hline 7. & $\mathrm{P}$ & 5.0 & $\begin{array}{c}20 \\
(\mathrm{p} 75)\end{array}$ & $\begin{array}{c}100 \\
(<\mathrm{p} 3)\end{array}$ & $\begin{array}{l}\text { April } \\
1993\end{array}$ & $\begin{array}{l}\text { Muntah } \\
\text { Dehidrasi }\end{array}$ & $\begin{array}{l}\text { ATR proksimal } \\
\text { LLA } \\
\text { Hepatitis B } \\
\text { Kandung kemih } \\
\quad \text { neurogenik }\end{array}$ & 2.4 & U \\
\hline 8. & $\mathrm{P}$ & 11.0 & $\begin{array}{c}18 \\
(<\mathrm{p} 3)\end{array}$ & $\begin{array}{c}120 \\
(<\mathrm{p} 3)\end{array}$ & $\begin{array}{c}\text { Agustus } \\
1994\end{array}$ & $\begin{array}{l}\text { Paralisis } \\
\text { periodik }\end{array}$ & $\begin{array}{l}\text { ATR distal } \\
\text { Insufisiensi } \\
\text { ginjal }\end{array}$ & 2.0 & Hidup \\
\hline 9. & $\mathrm{~L}$ & 1.0 & $\begin{array}{c}8.5 \\
(\mathrm{p} 10-25)\end{array}$ & $\begin{array}{c}74 \\
(\mathrm{p} 50)\end{array}$ & $\begin{array}{l}\text { Febr } \\
1995\end{array}$ & $\begin{array}{l}\text { Tungkai } \\
\text { bengkok }\end{array}$ & ATR proksimal & 1.9 & Hidup \\
\hline 10. & $\mathrm{~L}$ & 0.4 & $\begin{array}{c}3.2 \\
(<\mathrm{p} 3) \\
\end{array}$ & $\begin{array}{c}53 \\
(<\mathrm{p} 3) \\
\end{array}$ & $\begin{array}{c}\text { Mei } \\
1995 \\
\end{array}$ & $\begin{array}{l}\text { Muntah } \\
\text { Dehidrasi }\end{array}$ & ATR distal & 1.6 & Hidup \\
\hline 11. & $\mathrm{~L}$ & 3.5 & $\begin{array}{c}9 \\
(<\mathrm{p} 3)\end{array}$ & $\begin{array}{c}72 \\
(<\mathrm{p} 3)\end{array}$ & $\begin{array}{c}\text { Oktober } \\
1995\end{array}$ & Gagal tumbuh & ATR distal & 1.0 & Hidup \\
\hline 12 . & $\mathrm{L}$ & 5.0 & $\begin{array}{c}8.6 \\
(<\mathrm{p} 3)\end{array}$ & $\begin{array}{c}88 \\
(<\mathrm{p} 3)\end{array}$ & $\begin{array}{c}\text { Oktober } \\
1995\end{array}$ & $\begin{array}{l}\text { Tidak dapat } \\
\text { berjalan }\end{array}$ & ATR distal & 1.0 & Hidup \\
\hline
\end{tabular}

Keterangan: ATR: asidosis tubulus renalis, LLA: leukemia limfositik akut, ISK: infeksi saluran kemih

dihentikan selama 3 tahun dan terjadi infeksi saluran kemih setelah terdapat nefrokalsinosis.

Semua pasien mendapat pengobatan natrium bikarbonat dan kalium klorida, sedangkan terapi lain disesuaikan dengan gangguan asam basa, elektrolit, dan keadaan klinis. Tiga orang pasien yang meninggal semua menderita ATR proksimal, 2 orang diantaranya menderita sindrom Fancony dan satu menderita leukemia limfositik akut serta gagal hati.

\section{Diskusi}

Asidosis tubulus renalis merupakan penyakit yang jarang ditemukan. Di Massachusetts General Hospital, selama 32 tahun (1939-1971) didapatkan 21 kasus ATR atau 0,6 kasus per tahun. ${ }^{7}$ Hasil yang sama juga didapatkan di Bagian IKA FKUI-RSCM; selama 20 tahun didapatkan 12 kasus ATR atau kira-kira 0,6 kasus per tahun. Antara tahun 1975 sampai dengan 
Sari Pediatri, Vol. 4, No. 4, Maret 2003

Tabel 2. Hasil pemeriksaan laboratorium

\begin{tabular}{lcc}
\hline Hasil pemeriksaan & $\begin{array}{c}\text { Jumlah pasien } \\
\mathrm{n}=12\end{array}$ & $\%$ \\
\hline Darah & 7 & 58,3 \\
- $\mathrm{PH}<7,3$ & 12 & 100 \\
- $\mathrm{HCO}<20 \mathrm{meq} / \mathrm{l}$ & 9 & 75 \\
- $\mathrm{K}<3,0 \mathrm{meq} / \mathrm{l}$ & 91,7 \\
- $\mathrm{Cl}>106 \mathrm{mg} / \mathrm{dl}$ & 11 & 8,3 \\
- Fosfatase alkali meningkat & 75 & 91,7 \\
- Senjang anion plasma normal (8-16) & 11 & 75 \\
\hline Urin & & 58.3 \\
$\quad$ PH $>6$ & 9 & \\
Senjang anion positif & 7 &
\end{tabular}

1987 hanya didapatkan satu kasus ATR, dan sejak 1988 sampai 1995 didapatkan 11 kasus. Tampaknya kasus ATR semakin sering ditemukan atau mungkin karena kewaspadaan orangtua dan dokter terhadap kasus ini semakin meningkat.

Manifestasi klinis ATR tidak spesifik, dapat berupa gangguan pertumbuhan, asidosis metabolik, konstipasi, diare, muntah, anoreksia, poliuria dan dehidrasi. ${ }^{1,2,4}$ Pada penelitian ini lama waktu antara keluhan pertama sampai diagnosis ATR ditegakkan adalah 2 bulan sampai 4 tahun dengan rerata 1 tahun 3 bulan. Diagnosis ditegakkan cukup lama, mungkin disebabkan karena penyakit ini jarang ditemukan dan manifestasi klinis penyakit yang tidak spesifik sehingga orangtua ataupun dokter tidak memikirkan kemungkinan diagnosis ATR. Pada tahun 1981, Mc Sherry melaporkan satu kasus ATR pada bayi dengan manifestasi klinis muntah, diare, dan dehidrasi. Pasien sudah menderita keluhan ini sejak berusia 26 hari dan pernah dirawat beberapa kali dengan keluhan yang sama, tetapi baru setelah berumur 6 bulan diagnosis ATR ditegakkan. ${ }^{8}$

Peran jenis kelamin pada ATR tidak jelas. Dalam kepustakaan disebutkan bahwa 70\% ATR distal primer adalah perempuan tetapi pada sejumlah keluarga dilaporkan distribusi jenis kelamin yang sama. ${ }^{9} \quad$ Mc Sherry dkk., (1972) melaporkan 4 kasus ATR terdiri dari 1 laki-laki dan 3 perempuan. ${ }^{10}$ Brenner dkk. (1982) melaporkan 92 kasus ATR terdiri 36 laki-laki dan 56 perempuan, dan 35 di antara 44 ATR distal adalah perempuan. ${ }^{11}$ Igarashi dkk. (1990) melaporkan 4 kasus ATR terdiri dari 2 laki-laki dan 2 perempuan. ${ }^{12}$ Pada penelitian ini, jumlah laki-laki dan perempuan adalah sama masing-masing 6 orang. Jika dilihat berdasarkan kronologis, maka 3 pasien ATR pertama adalah 2 laki-laki dan 1 perempuan, kemudian diikuti dengan 5 pasien perempuan (1988-1994), dan selanjutnya pada tahun 1995 didapatkan 4 pasien lakilaki. Urutan jenis kelamin seperti ini mungkin merupakan faktor kebetulan. Pada ATR distal, lakilaki lebih banyak daripada perempuan yaitu 5 dan 2 kasus.

Asidosis tubulus renalis distal merupakan tipe ATR yang lebih sering ditemukan dibandingkan dengan tipe lain. Mc Sherry dkk. (1972) melaporkan 4 kasus ATR dan 3 di antaranya adalah tipe distal dan 1 tipe proksimal. ${ }^{10}$ Pada penelitian ini didapatkan 8 ATR distal dan 4 ATR proksimal. Brenner dkk. (1982) melaporkan 92 kasus ATR terdiri dari ATR distal 44 kasus, ATR proksimal 18 kasus, dan ATR tipe IV 30 kasus. ${ }^{11}$

Pada penelitian ini gangguan pertumbuhan didapatkan pada 10/12 (83,3\%) kasus. Gagal tumbuh terjadi karena beberapa hal, yaitu (1) meningkatnya pengeluaran sulfat dalam urin menyebabkan defisiensi sulfat sehingga terjadi gangguan pembentukan kondroitin sulfat dan mengakibatkan gangguan pertumbuhan. (2) Pada asidosis metabolik akan terjadi gangguan metabolisme kolagen yang akan mengakibatkan gangguan pertumbuhan. (3) Selain itu gangguan pertumbuhan dapat juga disebabkan gangguan metabolisme vitamin $\mathrm{D}$ dan mineral, atau pengaruh hormonal. ${ }^{3,4,5,13}$

Asidosis tubulus renalis ditandai dengan asidosis metabolik, hiperkloremia, dan urin yang alkali. Rentang $\mathrm{pH}$ plasma antara 7,07 - 7,37 dan $\mathrm{pH}<7,3$ didapatkan pada 7/12 (58,3\%) kasus; hasil ini tidak berbeda dengan laporan Whyte dkk. (1980) bahwa 
nilai $\mathrm{pH}$ darah pada pasien ATR $7.2-7.25 .{ }^{14} \mathrm{pH}$ urin berkisar antara 6.0 sampai $7.0 ;{ }^{6}$ Namun penelitian ini, rentang nilai $\mathrm{pH}$ urin adalah $5,0-8,0$ dan $9 / 12$ $(75 \%)$ pasien mempunyai $\mathrm{pH}$ urin $>6$.

Kehilangan kalium melalui urin dapat menyebabkan hipokalemia berat sehingga menimbulkan paralisis. Gejala muskuloskeletal seperti artralgia, mialgia dan low back pain sering ditemukan pada dewasa tetapi jarang pada anak. ${ }^{5,6}$ Gangguan muskuloskeletal merupakan manifestasi klinis dan keluhan utama yang paling sering ditemukan pada pasien ATR, diikuti dengan muntah dan dehidrasi serta gagal tumbuh. Kelumpuhan didapatkan pada $91,7 \%$ pasien kemungkinan disebabkan oleh hipokalemia, mengingat rentang kadar kalium plasma adalah 2,0 - 4,0 mEq/l. Sedangkan Whyte dkk. (1980) melaporkan kadar kalium pada pasien ATR antara 3,1-3,6 mEq/l. ${ }^{14}$

Pada ATR, terjadi penurunan rebsorbsi bikarbonat dan ekskresi ammonium yang menyebabkan asidosis hiperkloremia. Hiperkloremia ini terjadi karena kekurangan bikarbonat yang reabsorpsi di tubulus ginjal diganti oleh ion klor dan proses ekskresi ammonium di tubulus ginjal selalu disertai ekskresi ion klor dalam jumlah yang seimbang. ${ }^{3,6,15}$ Ditemukan rentang kadar Cl $100-122 \mathrm{mEq} / \mathrm{l}$ dan hiperkloremia didapatkan pada 7/12 (58,3\%), sedangkan Whyte dkk. (1980) melaporkan rentang kadar $\mathrm{Cl}$ antara $106-111 \mathrm{mEq} / \mathrm{l}^{14}$

Fungsi glomerulus umumnya normal pada anak yang menderita ATR pada usia muda, tetapi jika tidak diobati, maka penurunan progresif fungsi ginjal dapat terjadi dalam beberapa tahun akibat kerusakan parenkim ginjal. Insufisiensi ginjal dapat ditemukan walaupun jarang;,3,5,6,16 kita menemukan fungsi ginjal normal hanya 1 pasien mempunyai penurunan fungsi ginjal dengan penyebab yang tidak diketahui.

Kadar fosfatase alkali dapat meningkat jika terdapat lesi osteomalasia atau rikets; 4,5 Walaupun 58,32\% (7/ 12) kasus mengalami peningkatan kadar fosfatase alkali namun tidak ada data mengenai kelainan tulang secara radiologis. Kemungkinan pada ketujuh kasus ini telah terjadi kelainan tulang belum dapat disingkirkan. Gambaran radiologis pada ATR dapat berupa nefrokalsinosis, nefrolitiasis, dan osteomalasia. Pada penelitian Courey dan Pfister (1972) didapatkan nefrolitiasis pada $8 / 21$ kasus, nefrolitiasis $10 / 12$ kasus dan osteomalasia 6/12 kasus. ${ }^{7}$ Pada penelitian Brenner dkk. (1982) kelainan tulang didapatkan pada 17\% kasus. Nefrokalsinosis terjadi karena hiperkalsiuria, hiperfosfaturia, hipositraturia dan urin yang alkali.
Nefrokalsinosis dapat dideteksi dengan pemeriksaan ultrasonografi, CT-scan dan pemeriksaan histologis. ${ }^{11}$ Nefrokalsinosis lebih sering terjadi pada ATR distal daripada ATR tipe lainnya. ${ }^{6}$ Brenner dkk. (1982) melaporkan kalsifikasi ginjal pada 27 di antara 82 kasus ATR dan semuanya merupakan ATR distal dengan rincian nefrokalsinosis pada 24 kasus, nefrolitiasis 2 kasus, nefrokalsinosis disertai nefrolitiasis pada 1 kasus. ${ }^{11}$ Nefrokalsinosis pada penelitian ini didapatkan pada 2 pasien yang keduanya menderita ATR distal.

Prognosis ATR biasanya baik apabila diagnosis ditegakkan secara dini dan terapi yang adekuat dimulai sedini mungkin. Dengan terapi yang adekuat, sebagian besar komplikasi seperti nefrokalsinosis, nefritis interstisialis, kerusakan glomerulus, dan kelainan tulang dapat dicegah. Ekskresi kalsium akan normal dan pertumbuhan dapat mencapai keadaan normal. Sebaliknya, diagnosis dan terapi yang terlambat dapat menimbulkan komplikasi ${ }^{1,13,16}$ Pada penelitian ini, waktu antara terjadinya manifestasi klinis sampai dengan tegaknya diagnosis berkisar antara 2 bulan hingga 4 tahun. Hal ini akan mempengaruhi perjalanan penyakit sebagai berikut : kelainan tulang didapatkan pada 2/12 pasien dan kedua pasien ini didiagnosis setelah menderita penyakit 2 bulan dan 1 tahun 6 bulan. Satu kasus mengalami nefrokalsinosis setelah pengobatan dihentikan selama 3 tahun. Tiga pasien meninggal dengan penyebab sindrom Fancony dan leukemia limfositik akut, dan ketiga pasien ini merupakan ATR proksimal.

\section{Kesimpulan}

Asidosis tubulus renalis merupakan penyakit yang sangat jarang dengan manifestasi klinis yang tidak spesifik sehingga diagnosis sering terlambat. Gangguan motorik tungkai bawah merupakan keluhan utama yang paling sering ditemukan

\section{Daftar Pustaka}

1. Rodriquez-Soriano J, Vallo A. Renal tubular acidosis. Pediatr Nephrol 1990; 4:268-75.

2. Rodriquez-Soriano J. New insights into pathogenesis of renal tubular acidosis from functional to molecular studies. Pediatr Nephrol 2000; 14:1121-36.

3. Hanna JD, Santos F, Chan JCM. Renal tubular acidosis. Dalam:Kher KK, Kanwar SP, penyunting. Clinical 
Pediatric Nephrology, edisi ke-1. New York, McGrawHill Inc, 1992. h. 665-94.

4. Weber S, Soergel M, Jeck N, Konrad M. Atypical distal renal tubular acidosis confirmed by mutation analysis. Pediatr Nephrol 2000; 15:201-4.

5. Nagai R, Kohh SW, Balle JW, Fenton T, Halperin ML. Renal tubular acidosis and osteopetrosis with carbonic anhydrase II deficiency: pathogenesis of impaired acidification. Pediatr Nephrol 1997; 11:633-6.

6. Rodriquez-Soriano J. Renal tubular acidosis. Dalam: Edelmann CM, penyunting. Pediatric Kidney Disease, edisi ke-2, London, Little Brown, 1992. h. 1737-64.

7. Courey WR, Pfister RC. The radiographic findings in renal tubular acidosis. Radiology 1972; 105:497-503.

8. McSherry E. Renal tubular acidosis in childhood. Kidney Int 1981; 20:799-809.

9. Gauthier B, Edelmann CM, Barnett HL. Metabolic acidosis. Dalam: Gauthier B, penyunting. Nephrology and Urology for the pediatrician, edisi ke-1. Boston, Little Brown, 1992. h.49-56.

10. McSherry E, Sebastian A, Morris RC. Renal tubular acidosis in infants: several kinds, including bicarbonate wasting, classical renal tubular acidosis. J Clin Invest
$1972 ; 51: 499-511$.

11. Brenner RJ, Spring DB, Sebastian A, McSherry E, Genant HK, Palubinskas AJ, dkk. Incidence of radiographically evident bone disease, nephrocalcinosis, and nephrolithiasis in various type of renal tubular acidosis. N Engl J Med 1982; 307:217-21.

12. Igarashi T, Kawato H, Kamoshita S. Reversible low molecular weight proteinuria in patents with distal renal tubular acidosis. Pediatr Nephrol 1990; 4:593-6.

13. CarlisleEJF, Donnely SM, Halperin ML. Renal tubular acidosis (RTA): Recognize The Ammonium defect and pHorget the urine $\mathrm{pH}$. Pediatr Nephrol 1991;5:242-8.

14. Whyte MP, Murphy WA, Fallon MD, Sly WS, Teitelbaum SLL, McAlister WH dkk. Osteoporosis, renal tubular acidosis and basal ganglia calcification in three sisters. Am J Mef 1980; 69:64-74.

15. McSherry E, Morris RC. Attainment and maintenance of normal stature with alkali therapy in infants and children with classical renal tubular acidosis. J Clin Invest 1978; 61:509-27.

16. Wrong O. Distal renal tubular acidosis: the values of urinary $\mathrm{pH}, \mathrm{pCO} 2$ and $\mathrm{NH}_{4}^{+}$measurements. Pediatr Nephrol 1991; 5:249-55. 